\title{
Effects of varying modality, surface features, and retention interval on priming in word-fragment completion
}

\author{
HENRY L. ROEDIGER III and TERESA A. BLAXTON \\ Purdue University, West Lafayette, Indiana
}

\begin{abstract}
Subjects in Experiment 1 studied a list of words under varying presentation conditions (visual or auditory) and in two typographies within the visual condition (typed or hand printed) and then received a word-fragment completion test (e.g., _YS_E_Y for mystery) in which the test cues also varied in typography. The main findings were that (1) priming occurred for all study items, relative to nonstudied items, but greater priming occurred for visual than for auditory presentation, and (2) performance in the visual conditions was better when typographies matched between study and test than when the typographies mismatched, but only for words studied in hand-printed form. These findings were generally replicated when the test was delayed 1 week, although priming declined across this retention interval (Experiment 2). In Experiment 3 subjects studied words that were either in focus or blurred and showed greater priming when test fragments were presented in the same manner as at study. Priming in the word-fragment completion task depends on matching surface characteristics of items between study and test and exemplifies the requirement of performing similar mental operations at study and test for maximizing performance (transfer-appropriate processing).
\end{abstract}

In the present series of experiments, we explored a task for investigating memory that was introduced by Tulving, Schacter, and Stark (1982). Following presentation of a list of words, their subjects received two forms of test either $1 \mathrm{~h}$ or 1 week later. One test was a standard yes/no recognition test in which previously studied target words were intermixed with an equal number of new words, and the subjects' task was to identify the target words. In the novel task, subjects were presented with fragmented versions of the words (half studied, half not) and told to complete them with the first word that came to mind. The fragmented words constituted word frames that permitted only a single completion (e.g., A __ $\mathrm{A}_{-}$IN for assassin). This fragment completion task represents a variant of other tasks in which subjects receive various parts of words and attempt to complete them (Warrington \& Weiskrantz, 1970), although the more usual forms of the task involve perceptually degrading all letters in the word or presenting only the first few letters of the word (e.g., dre- for dream). This last type of test has been most frequently studied (e.g., Graf, Squire, \& Mandler, 1984); relative to words in the fragment completion task under study here, target words in

This research was supported by Grant RO1 HD-15054 from the National Institute of Child Health and Human Development. We thank Bradford Challis, Alice Healy, Neal Johnson, James Neely, Douglas Nelson, and Endel Tulving for their comments on previous versions of this paper. A preliminary report of these results was presented at the meeting of the Psychonomic Society in San Diego in November, 1983. The second author is now at BDM Corporation, McLean, Virginia. Requests for reprints may be sent to Henry L. Roediger III, Department of Psy. chological Sciences, Purdue University, West Lafayette, IN 47907. that task are typically of higher frequency (at least 10 completions are possible) and subjects respond more rapidly. The measure of interest in the word-fragment completion tasks is the amount of direct (or repetition) priming, or the greater completion level of recently studied words over that of similar nonstudied words.

Tulving et al. (1982) reported two interesting findings. First, a sizable priming effect was obtained in fragment completion, and it was relatively invariant between $1 \mathrm{~h}$ and 1 week. Thus, priming in the word-fragment completion task reflects learning from recent experience, but this learning seems surprisingly more resistant to forgetting than is learning as reflected in other measures of retention. (Recognition memory dropped sharply over the 1 -week delay in the Tulving et al. experiment.) A second finding indicated another form of independence between recognition memory and priming in word-fragment completion: when subjects were given a recognition test followed by the fragment completion test, performance on the two exhibited stochastic independence. Thus the Tulving et al. (1982) experiment produced two results that seem to indicate that word-fragment completion and recognition memory rely on different memory systems, or at least that they access different types of memory representation.

The word-fragment completion task developed by Tulving et al. (1982) is only one of some half dozen or so tasks that have been developed to study retention indirectly through repetition priming (see Shimamura, 1986, for a review of this work with reference to amnesic patients). In all of these tasks, subjects' retention is measured in directly by their increased accuracy or speed of process- 
ing of a word (or other form of material) due to its recent exposure. Because subjects are usually told to respond with the first item that comes to mind and frequently are not informed that their memories are being tested, Graf and Schacter (1985) have called these indirect measures implicit measures of retention. These measures are contrasted with more standard means of testing retentionrecall, recognition, frequency judgments, and the likein which subjects are directly told to retrieve presented information. These traditional measures may thus be termed explicit measures of retention.

A most interesting aspect of the research to date is that many experimental dissociations have been shown between explicit and implicit measures of retention. Independent variables and subject variables (amnesics vs. normals, usually) often show one pattern of performance on explicit tests, but a completely different pattern on implicit tests, as in the Tulving et al. (1982) experiment. (See Jacoby \& Witherspoon, 1982, and Roediger \& Blaxton, 1987, for partial reviews.) In the most interesting cases, implicit measures reveal evidence of retention under conditions (e.g., amnesia) when explicit measures do not (e.g., Graf et al., 1984; see Shimamura, 1986, for a review).

Given the interest in these new measures of retention, further examination of their basic properties is in order. In the present series of experiments, we examined the effects of several variables on priming in word-fragment completion. However, the choice of variables was determined by prior research with other tasks that have been more thoroughly studied, and this relevant evidence will be reviewed first. The implicit tasks of most direct concern to the present work are (1) perceptual identification, or reporting words that are flashed briefly (Jacoby \& Dallas, 1981; Winnick \& Daniel, 1970), and (2) wordstem completion in which words are completed from three-letter stems (e.g., Graf \& Mandler, 1984; Graf, Mandler, \& Haden, 1982).

Jacoby and Dallas (1981, Experiment 1) had subjects study words under graphemic, phonemic, and semantic orienting conditions in the standard levels-of-processing paradigm (e.g., Craik \& Tulving, 1975) by having them make judgments about each word that emphasized the relevant aspect of the words. Retention was tested by having subjects either discriminate previously seen words from distractors in a standard recognition task or identify words from briefly presented exposures (around $30-35 \mathrm{msec}$ ) in a perceptual identification task. Variation in encoding conditions produced the typical robust effect on recognition memory, with semantic encoding producing better performance than phonemic encoding, which in turn surpassed graphemic encoding. However, no effect of this variable was found on perceptual identification in which no explicit decision about having previously studied the items was required. The identification measure was not insensitive, since items that had been studied previously were identified better than were nonstudied words.

In related experiments, Jacoby and Dallas (1981, Experiments 2 and 3 ) had subjects either read words or un- scramble their letters to solve an anagram. The items constructed from scrambled letters were better recognized than those read, but this manipulation did not influence the magnitude of priming in perceptual identification. Perceptual identification was not simply insensitive to any manipulation, because in Experiment 6 Jacoby and Dallas (1981) showed that modality of presentation had a large effect. Words presented visually produced substantial priming effects on later perceptual identification, but words presented auditorily produced no priming at all.

More recently, Jacoby (1983) provided an account for such results by proposing that the distinction between datadriven (bottom-up) and conceptually driven (top-down) processing applies to retention tests as it does to tasks used to study perception. On an implicit memory test such as perceptual identification in which subjects are to identify isolated words from brief glimpses, processing should depend heavily on characteristics of the data display and the match of such perceptual features during study and test. Thus visual presentation produces substantial priming on visual identification, whereas auditory presentation does not. To provide further supporting evidence, across several experiments Jacoby (1983) found that when subjects read words (e.g., cold) rather than generating them from their antonyms (hot-???), later perceptual identification was superior. This finding represents a reversal of the usual generation effect in explicit tests in which generated material is typically better retained than material that is read. Indeed, Jacoby (1983) found the standard advantage of generated over read items on a yes/no recognition memory test in these experiments. The fact that physical presentation of the word in the read condition transfers better to the perceptual identification test supports its classification as a data-driven task.

In summary, Jacoby's (1983) basic argument is that tasks such as perceptual identification are data-driven in the sense that the match between the physical formats of study and test stimuli is quite important, and conceptual factors (e.g., levels of processing) are not. On the other hand, conceptually driven tests, such as free recall or recognition, benefit from coding activities that encourage conceptual elaboration of the material. The research reviewed above and other evidence (Jacoby \& Hayman, $1987)$ is largely in line with this proposal, because perceptual identification is sensitive to presentation format (visual presentation produces greater priming than auditory presentation; words that are read produce better priming than those that are generated) and largely insensitive to conceptual manipulations (reading a word vs. solving an anagram, variation in orienting tasks). On the other hand, recognition and especially free recall are less sensitive to the format of item presentation (auditory or visual), but quite sensitive to conceptual manipulations such as levels of processing. ${ }^{1}$

Other implicit priming tasks also produce results that are generally consistent with the notion that they rely on data-driven processing. In the word-stem completion task, greater priming occurs when the study items are presented visually rather than auditorily, although in this task (un- 
like in perceptual identification) cross-modal priming does occur (Graf, Shimamura, \& Squire, 1985). In addition, variation in levels of processing induced by manipulating orienting tasks produces large effects on cued recall with word-stem cues, but has only slight effects (that are usually not statistically significant in any one experiment) on word-stem completion. Other implicit memory tests, such as facilitation in reading inverted text (Kolers, 1975) and repetition priming in the lexical decision task (Kirsner, Milech, \& Standen, 1983), also show large effects of mode of presentation and thus may also be tentatively considered as data-driven tasks (see Kolers \& Roediger, 1984).

The foregoing considerations led us to ask whether priming in the word-fragment completion test is similarly sensitive to changes in the surface form of information between study and test, because data are lacking as to whether such variables as modality (auditory or visual) or visual features (e.g., induced by typographic manipulations) affect the magnitude of priming in Tulving et al.'s (1982) fragment completion task. One could imagine that performance on word-fragment completion tasks may be insensitive to changes in surface form, unlike performance on other implicit tasks. The reason is that word-fragment completion, unlike the other tasks mentioned above that call for rapid processing of data displays, seems to require a slow, laborious fitting together of letter combinations (e.g., $E_{-} S_{-} A_{-}, R_{-} \mathrm{YR}_{-} I D$, or _ I $\mathrm{AMO}_{-}$.) Tulving et al. (1982) permitted subjects an average of $25 \mathrm{sec}$ per fragment; during such extended intervals, subjects (arguably) may call upon conceptual processes rather than rely on retention of surface features of the studied information. Thus, repetition priming in this paradigm, unlike in other implicit tasks, may not be data-driven.

Experiment 1 was designed to answer three questions. First, does modality of presentation affect priming on the (visual) word-fragment completion tosk? If the task is completely data-driven, then no priming from auditory presentations should be found, just as Jacoby and Dallas (1981) reported for perceptual identification. If it is completely conceptually driven, then no modality effect should be found in long-term retention, as in free recall. Second, within the visual modality, does typographic similarity between study and test presentations affect performance, as it does in perceptual identification (Jacoby \& Hayman, 1987) and reading inverted text (e.g., Kolers \& Perkins, 1975)? Third, assuming that word-fragment completion is at least partly data-driven, can having subjects imagine the "data" at study enhance priming? Jacoby and Witherspoon (1982, p. 315) reported that asking subjects to spell auditorily presented words enhanced their later perceptual identification. We tried a related manipulation here with the fragment completion task.

\section{EXPERIMENT 1}

In Experiment 1 all subjects studied 96 words and then received a test a few minutes later. At study, 48 words were presented auditorily and 48 visually. Of the latter, 24 were typed in lowercase letters and 24 were printed by hand in uppercase letters. For 24 words presented auditorily, the subjects were told to try to form an image of the word as it would appear typed in lowercase letters; no special instruction preceded the other 24 auditorily presented words. We thought that having the subjects imagine the words' appearances might provide representations that would be useful on the later fragment completion test.

The subjects received the word-fragment completion test in which they were given word frames and asked to fill in the missing letters, if possible, in the time permitted. Fragments representing the 96 previously presented words were randomly intermixed with fragments for 96 nonstudied words from an alternate base list of items. In addition, half the items in both sets were presented in typed lowercase letters and half were presented in uppercase, hand-printed letters. This variable (typography at test) was completely crossed with the four study conditions.

\section{Method}

Subjects. We tested 64 Purdue undergraduates, who participated as one way to fulfill a course requirement in introductory psychology.

Materials. Stimuli for the experiment were word fragments having only one appropriate solution (e.g., _YS_E_Y for mystery). The materials were drawn largely from the pool of items used by Tulving et al. (1982). Twenty-six of their 192 nouns were replaced with new ones thought to be more familiar to Purdue undergraduates. Items ranged in length from 6 to 12 letters. Fragments were generated for the 192 words used in the experiment, and norms were collected prior to experimentation to ensure that the nonstudied completion rate was approximately $30 \%$. To achieve this rate, the pattern of omitted letters differed in some cases from that used by Tulving et al. (1982) for some items.

Design. Two base lists of stimuli comprising 96 items each were constructed. Although all subjects were eventually tested on all 192 items, only one base list was presented for study. The studied base list was counterbalanced across subjects so that half of the subjects studied Base List 1 and the other half studied Base List 2. Within a base list, items were presented in the same order for study to all subjects. Each base list was divided into four blocks of 24 items each for presentation. The subjects studied each of these four blocks in one of four presentation conditions: typed, printed, auditory, and auditory/image typed. In the typed input condition, items were presented typed on sheets of paper in lowercase letters, whereas in the printed input condition, words were printed by hand in uppercase letters. In the auditory input condition, the experimenter read each word aloud to the subjects. Finally, in the auditory/image typed condition, the subjects were instructed to imagine, as they listened to each word, how it would appear if it were typed in lowercase letters. Each subject studied 24 items in each of these presentation conditions, but presentation conditions were rotated through the four blocks of items so that items were presented equally often in each study condition across subjects. The four presentation conditions were realized completely within subjects.

Procedure. The subjects were tested in groups of 1 to 4, with each experimental session proceeding as follows. The subjects were told that they would study a series of four word lists and that they would later be tested on the items, although the nature of the memory test was not specified. Each list of 24 items from each presentation condition was presented separately at the rate of $5 \mathrm{sec}$ per item. 
In the printed and typed input conditions, each subject was given a sheet of paper on which the words were written. One of 2 male experimenters paced the subjects through the 24-item segments by saying "next" every $5 \mathrm{sec}$. Each subject moved a cover sheet down the page as each new item was studied and was told to study the appropriate item and not to look ahead or lag behind. In the auditory conditions the experimenter simply read a new item aloud every $5 \mathrm{sec}$. There was a short break between each of the four lists as the experimenter collected and distributed stimulus study sheets for the visual conditions.

Study sheets were collected following presentation, and the subjects began a series of four fragment completion tests. The order of tests corresponded to the order in which blocks of items had been studied, so that the first test contained items from the first of the four blocks and so on. Each test contained 48 items, 24 of which had been studied and 24 of which were new, presented in a random order. New items were taken from the corresponding block of items in the nonstudied base list. Thus subjects studying different base lists saw exactly the same tests, with the studied items for half of the subjects being nonstudied items for the other subjects and vice versa. In addition, half the items on the tests were printed by hand and half were typed. Test lists were constructed so that an item presented in a particular input condition was tested half the time in a hand-printed form and half the time in typed form across subjects. The subjects were told that half of the fragments on their tests would correspond to items they had studied previously but that half would correspond to new items; however, they were told simply to complete each fragment with the first word that came to mind. They were given practice with a fragment corresponding to a nonstudied item before testing began, so that it was clear to them that the task could be performed without their explicitly trying to remember items presented earlier in the experimental context. They were given $20 \mathrm{sec}$ to complete each item and were told not to look ahead or to regress during the test. The entire experiment lasted approximately 90 min. $^{2}$

\section{Results and Discussion}

The results are presented in Table 1, where the proportion of correctly completed fragments is provided for each combination of study and test conditions. Reliable priming effects were found in all study conditions, with higher completion rates for studied than for nonstudied items. (All effects referred to as reliable exceed the .05 level of confidence.) A preliminary analysis of variance (ANOVA) revealed that the effect of priming was highly reliable $[F(1,63)=372.79, M S e=.034]$, with primed items and unprimed items being completed with average probabilities of .49 and .27 , respectively.

The three questions motivating Experiment 1 can be answered by considering performance in the four conditions in which the subjects saw or heard presentations of the words prior to the fragment completion test (the primed conditions). First, does a modality effect occur in word- fragment priming? The answer is yes: Relative to performance in the uninstructed auditory condition, subjects' performance was better when presentation was visual (.43 to .53 , combining over whether the material was presented printed or typed at study and test). Thus fragment completion behaves in part like a data-driven task, because it is sensitive to the match of surface features between study and test presentations. However, unlike performance in the perceptual identification task (Jacoby \& Dallas, 1981), reliable cross-modal priming did occur in fragment completion (.43 following auditory presentation vs. .27 for nonstudied items). ${ }^{3}$

Second, do typographic features affect the amount of priming? Within the visual presentation conditions, performance was better when items were studied and tested in the same typography than when typographies were switched between study and test. In the condition in which subjects saw hand-printed words at study and were tested with hand-printed fragments, they completed .59 correctly, relative to .52 in the printed-typed condition. A similar, although smaller and nonsignificant, trend appeared when items were presented typed and then tested either typed (.51) or printed (.48). Thus, some evidence here also points to the data-driven nature of word-fragment completion.

Third, can subjects generate (imagine) "data" that will enhance fragment completion priming? Performance was higher in the condition in which subjects were presented items auditorily but told to form images of the words typed (.49) than in the uninstructed auditory condition (.43), but this facilitation was not specific to the typed testing format. Apparently, the extra processing created by instructions to imagine typed words did not produce typographic encoding specific to the instructed form.

Inferential statistics verified the trends just described. A 4 (study condition) $\times 2$ (type of test) ANOVA on the primed items revealed a main effect of study condition $[F(3,189)=11.49, M S \mathrm{e}=.030]$ but no reliable effect of test condition $[F(1,63)=2.22, M S e=.019$, $p>.10$, and a marginally reliable study condition $\times$ test condition interaction $[F(3,189)=2.60, M S e=.021$, $p=.06]$. Least significance difference tests based on the MSe for the study condition $\times$ text condition interaction showed that performance in both of the auditory/image typed conditions was superior to that in the auditory conditions $(L S D=.05)$. Similarly, performance in the visual study conditions was generally better than that in the uninstructed auditory conditions, confirming an effect of study

Table 1

Proportion of Fragments Completed in Each Condition of Experiment 1

\begin{tabular}{lcccccc}
\hline & \multicolumn{5}{c}{ Study Condition } \\
\cline { 2 - 3 } \cline { 5 - 6 } Test & \multicolumn{2}{c}{ Visual } & & \multicolumn{2}{c}{ Auditory } & \\
\cline { 2 - 3 } Condition & Hand-Printed & Typed & & Instruction & $\begin{array}{c}\text { Image-Typed } \\
\text { Instruction }\end{array}$ & Nonstudied \\
\cline { 2 - 3 } Hand-Printed & .59 & .48 & .44 & .49 & .27 \\
Typed & .52 & .51 & .42 & .48 & .27 \\
\hline
\end{tabular}


modality on priming in visual word-fragment completion. In addition, performance in the printed-printed condition was reliably better than that in the other three visual study conditions. However, the typed-typed condition was not statistically different from the typed-printed condition.

A subsidiary $2 \times 2$ analysis of variance was conducted on the visual study conditions, with the factors being study mode and test mode (typed vs. printed for each). The analysis revealed a reliable effect of study mode $[F(1,63)=$ $8.44, M S e=.027]$, no reliable main effect of test mode $[F(1,63)=1.66, M S \mathrm{e}=.018]$, and a reliable interaction between the two $[F(1,63)=7.33, M S e=.022]$. The interaction was mainly produced by superior performance in the condition in which subjects both studied and were tested with printed items. Performance in this condition surpassed that in the other three, which did not differ among themselves $(L S D=.05)$.

Another way of portraying the fragment completion data is to order them according to the similarity between study and test conditions. When both study and test items were visually presented in the same typography, performance averaged .55; with visual presentation and different typographies, .50; with auditory presentation and no instruction to image the word, .43; and when the items had not been studied, .27 . Auditory presentation with instructions to imagine the word as being typed produced performance roughly equivalent to that of the visual presentation condition when the study and test typographies mismatched (.49).

\section{EXPERIMENT 2}

Four primary results of Experiment 1 were reliable cross-modal priming in word-fragment completion, greater same-modal than cross-modal priming, some evidence for greater priming in the visual mode when typographic features matched between study and test, and enhanced priming from auditory presentations when subjects were instructed to imagine the words. One purpose of Experiment 2 was to replicate some findings from Experiment 1 . In particular, evidence for specificity of visual features in priming was rather weak in Experiment 1 and deserved further examination. We attempted to replicate the strongest evidence for specificity of visual features obtained in Experiment 1, namely, differential transfer of typed and hand-printed words during study to a handprinted fragment completion test.

The second purpose of Experiment 2 was to examine the effects of changes in modality and typography on priming 1 week after study. We thus attempted to replicate Tulving et al.'s (1982) surprising finding of no decay in priming over this period. We also sought to determine whether the effects of perceptual characteristics (modality, typography) would vanish with delay. One popular view of retention of surface features is that they affect performance on relatively immediate tests, but that the perceptual record fades with time (e.g., Sachs, 1967). If so, priming may then be equivalent across visual and au- ditory conditions after 1 week, supported in both cases by an abstract representation of the studied words. On the other hand, since priming in implicit memory tasks has been shown to last $48 \mathrm{~h}$ for perceptual identification (Jacoby \& Dallas, 1981), from 1 to 5 weeks for wordfragment completion (Komatsu \& Ohta, 1984; Tulving et al., 1982), and possibly even 1 year for reading inverted text (Kolers, 1976), the engrams of experiences may record features of the original data for long periods, which would in turn support such long-lived priming effects in data-driven tests.

The subjects studied 96 words in three blocks of 32 , with one block presented printed, one presented typed, and one presented auditorily. The subjects were then tested on 96 fragments (half old, half new), both soon after presentation and again after a delay of 1 week. Printed fragments were always used during testing.

\section{Method}

Subjects and Design. Seventy-two Purdue undergraduates served as one way of completing a course requirement. The variables of study condition (typed, printed, auditory) and retention interval (immediate or 1-week delay) were manipulated within subjects.

Materials. The same materials were used as in Experiment 1, except that groups of 32 items were randomly assigned for counterbalancing purposes. The subjects studied 32 items in each of the input conditions, and then half of these items were tested immediately and half were tested after a 1-week delay (randomly interspersed, in both cases, with an equal number of nonstudied fragments). Across subjects, the six sets of 32 items were rotated through all conditions so that all items contributed equally to each condition.

Procedure. The procedure was similar to that used in Experiment 1 . All subjects were tested by the same female experimenter. After initial instructions, the subjects were presented 96 items in blocks of 32. Prior to each block, the presentation condition was described and then the items were presented at a 5-sec rate. Following presentation, the subjects were given instructions for the fragment completion test (lasting about $2 \mathrm{~min}$ ) and then given 96 fragments (half studied, half not) with instructions to complete each within the allotted 20 -sec period. The average retention interval between study and test of an individual item was estimated at $20 \mathrm{~min}$. At the end of this initial session, which lasted about 50 min, subjects were instructed to return at the same time the following week for another session (the nature of which was not specified). Twelve subjects failed to return and were replaced by others from the same pool. Because the design was realized completely within subjects, such attrition can have no deleterious consequences on the conclusions drawn.

At the second session, testing instructions were repeated and the subjects were given 96 more fragments at a $20-\mathrm{sec}$ rate (again, half were old and half new). Following this 35- to 40-min session, the subjects were debriefed and excused from the experiment.

\section{Results}

The proportions of fragments completed for both studied and nonstudied items are shown in Table 2. The main findings were that (1) the same dependency found in Experiment 1 between mode of presentation and amount of priming in word-fragment completion was obtained here on the immediate test, (2) a priming effect was found for both the immediate and delayed tests, and (3) the amount of priming dropped over the retention interval for all three conditions in which items were studied. 
Table 2

Fragment Completion Performance in Experiment 2 With Hand-Printed Fragments

\begin{tabular}{lcccc}
\hline & \multicolumn{4}{c}{ Study Condition } \\
\cline { 2 - 5 } Test Condition & Hand-Printed & Typed & Auditory & Nonstudied \\
\hline Immediate (20 min) & .53 & .48 & .42 & .22 \\
Delayed (1 week) & .44 & .36 & .35 & .26 \\
Difference (I-D) & .09 & .12 & .07 & \\
\hline
\end{tabular}

Statistical analyses confirmed these trends. An ANOVA on all the data showed a main effect-a priming effectfor studied versus nonstudied items $[F(1,71)=529.12$, $M S \mathrm{e}=.023]$ and a significant interaction with test delay $[F(1,71)=77.03, M S \mathrm{e}=.020]$. The magnitude of the priming effect was greater at the immediate test $(.26)$ than at the delayed test (.12). However, priming was still obtained after a 1-week delay, as confirmed by a least significance difference test $(L S D=.05)$.

A second ANOVA was conducted on data from only studied items. This revealed a reliable main effect of study condition $[F(2,142)=17.85, M S e=.030]$, with performance best in the printed condition (.48), worst in the auditory condition (.39), and intermediate in the typed condition (.42). A least significant difference test showed that on the immediate test, performance in all three conditions differed reliably from one another, whereas on the delayed test, completion in the printed study condition was greater than in the other two conditions, which did not differ $(L S D=.05)$. These findings generally confirmed those of Experiment 1. All test fragments were presented printed, and thus performance was best when the surface characteristics at study matched those at test. Performance was next best when both study and test modes were visual but with typographies not matched, and worst (at least for immediate testing) when study presentation was auditory and the test was visual. Even in this condition, however, reliable priming occurred for both immediate and delayed tests. Thus, as in Experiment 1, significant cross-modal priming was found.

An ANOVA on performance in the studied conditions also showed a reliable effect of retention interval $[F(1,71)$ $=77.94, \mathrm{MSe}=.019]$, but no interaction of study condition and retention interval $[F(2,142)=1.44$, $M S e=.023$ ]. Unlike Tulving et al. (1982), we found significant forgetting on a fragment completion task over a 1-week retention interval, and this loss was unaffected by the match between features of the study and test stimuli. Thus, the effects of varying perceptual features on priming in word-fragment completion was still evident after a week. We discuss these aspects of the data below, after presentation of Experiment 3.

\section{EXPERIMENT 3}

The results from the previous experiments consistently showed a strong modality effect on visual word-fragment completion on immediate tests: words presented visually were completed better than those presented auditorily.
However, the evidence that specific visual features played an important role was less clear cut. When subjects were given the hand-printed test, they performed better when they had studied hand-printed rather than typed words in both experiments, but no reliable effect of study typography was found in Experiment 1 when subjects were given the typed form of the fragment completion test.

Because the finding of specificity of visual features is critical to classification of word-fragment completion as a data-driven task, we used a new manipulation in Experiment 3 to provide a further test. The subjects studied words on slides that were presented either in clear focus or moderately blurred at study. (When blurred, words could be read, but only with difficulty.) At test the word fragments were similarly presented either in focus or blurred. We expected that subjects would complete blurred fragments better when words had previously been studied under blurred conditions rather than in clear focus and that the converse should occur for fragments presented clearly at test. ${ }^{4}$

This expectation is bolstered by results from an experiment by Dallett, Wilcox, and D'Andrea (1968). They had subjects study pictures either in focus or blurred and then gave them a recognition test in which test items were presented either focused or blurred. Better recognition occurred when the study and test forms matched (focusedfocused and blurred-blurred conditions) than when they mismatched (focused-blurred and blurred-focused conditions).

\section{Method}

Subjects. Twenty-four Purdue undergraduates served as subjects in the experiment in partial fulfillment of an introductory course requirement.

Materials. Stimuli for the experiment were similar to those used in Experiments 1 and 2, but constituted a new set of 128 words developed in conjunction with a related line of research (Blaxton, 1985). Word fragments were constructed for all words and uniquely specified the target. Words ranged in length from 5 to 12 letters, and the nonstudied completion rate was approximately $28 \%$ in a norming study for items included in the experiment.

Design. The 128 items were arbitrarily divided into two base lists of 64 items each. Each subject studied one base list and was then tested on both base lists. The base list presented for study was counterbalanced so that each base list was studied equally often across subjects. Each base list was divided into two segments of 32 items each. Items were presented on slides for study with one block focused normally and the other block blurrred. The blurred items were unfocused to a degree that they were still readable, although difficult to discern. Items were always presented in the same order for study, but the order of study conditions was counterbalanced so that words occurred equally often in each condition across subjects.

Following study, each subject received a word-fragment completion test in which fragments corresponding to all 128 items were presented on slides. As in the study phase, half of the fragments were presented in a block of slides in focus and half in a block of blurred slides. Each block contained equal numbers of studied and nonstudied items randomly ordered. Nonstudied items were drawn from the corresponding segments of the nonstudied base list. Test items were always presented in the same order, with test condition counterbalanced so that each item appeared in each condition equally often across subjects. These manipulations yielded a 2 (study con- 
dition: focused vs. blurred) $\times 2$ (test condition: focused vs. blurred) factorial design that was realized completely within subjects.

Procedure. The subjects were tested individually, with procedures otherwise similar to Experiments 1 and 2. They were told that they would be studying a list of words before taking a memory test, although its nature was unspecified. The subjects were given study instructions prior to each of the two study blocks. Prior to seeing focused items, the subjects were instructed that they would see words presented one at a time on slides for $5 \mathrm{sec}$ each and were asked to read each word aloud as it was presented. Similar instructions were given prior to the blurred block of items, but the subjects were also warned that the items would be presented out of focus. Each subject received standardized slide projector settings for focused and blurred stimulus presentation. On rare occasions when a subject was unable to read an item during the 5 -sec presentation interval, the experimenter read it aloud as the projector changed to the next slide.

Following this initial study phase, the subjects were given in structions for the word-fragment completion task. They were shown examples of fragments corresponding to nonstudied items to illustrate the nature of the task. Both focused and blurred practice items were presented. The subjects were also informed that half of the fragments on the test would correspond to studied items and half to new words, but that they should always respond with the first correct completion that came to mind. Fragments were presented individually on slides for $15 \mathrm{sec}$ each, and subjects wrote solutions to fragments on a blank sheet of paper as they appeared. This experimental session lasted approximately $45 \mathrm{~min}$.

\section{Results}

The proportion of fragments completed as a function of study and test conditions in Experiment 3 are presented in Table 3. As may be seen, large priming effects were obtained in that completion rates for studied items were much higher than those for nonstudied items. A preliminary ANOVA including data for nonstudied items confirmed this observation with a main effect of study condition $[F(2,23)=171.08, M S \mathrm{e}=.025]$. Studied items were completed with an average probability of .64, compared with a completion rate of .28 for nonstudied items. Completion rates for focused and blurred nonstudied items did not differ.

In considering the data from only the studied conditions, a strong effect of match in stimulus quality between study and test is apparent. Specifically, performance was better when items were studied and tested in the same physical form than when the quality of the stimulus was changed between study and test. Items originally presented focused were more likely to be completed given focused (.71) than blurred fragments (.57). Likewise, and more interestingly, items studied in a blurred form were better completed in the blurred test condition (.70) than in the focused condition (.59). An ANOVA showed that this study $\times$ test interaction was reliable $[F(1,23)=17.39$, $M S \mathrm{e}=.022]$. With an $L S D$ of .08 , performance levels

Table 3

Fragment Completion Performance in Experiment 3

\begin{tabular}{lccc}
\hline & \multicolumn{3}{c}{ Study Condition } \\
\cline { 2 - 4 } Test Condition & Focused & Blurred & Nonstudied \\
\hline Focused & .71 & .59 & .29 \\
Blurred & .57 & .70 & .27 \\
\hline
\end{tabular}

were higher in the conditions in which the physical form of test stimuli matched those studied earlier than in conditions in which the physical stimulus was altered between study and test. There were no main effects of stimulus quality for either study or test (both $F \mathrm{~s}<1$ ).

Results from this experiment, together with evidence in Experiments 1 and 2, argue that the word-fragment completion task is quite sensitive to the physical match in visual stimuli between study and test. Changes in typography and stimulus quality between study and test reduced the amount of priming obtained for studied items. Fragments were most likely to be completed in all experiments under conditions in which subjects encountered stimuli in the same physical form at both study and test

\section{GENERAL DISCUSSION}

The main findings from the experiments reported here were that (1) priming in the word-fragment completion task was greater when the presentation of the targets was visual rather than auditory, although auditory presentation also produced priming; (2) priming was enhanced within visual presentation conditions when the test typography matched that used used at study, although this effect was confined to performance in the printed test conditions; (3) a similar, but stronger, effect was observed when congruity between study and test presentations was varied by presenting items blurred or in focus; (4) fragment completion performance dropped over a 1 -week retention interval; and (5) specificity of visual features persisted over a week.

The finding of decay in priming over 1 week differs from the findings of Tulving et al. (1982), who reported no decline in fragment completion priming over the same period. Even though Komatsu and Ohta (1984) replicated Tulving et al.'s (1982) finding, we regard the subjects' forgetting in Experiment 2 as quite real. The reason is that a recent series of experiments reported by Sloman, Hayman, Ohta, Law, and Tulving (in press) revealed consistent evidence of forgetting in primed fragment completion, even over relatively short retention intervals. Their evidence confirms our finding in Experiment 2.

In the remainder of this section, we discuss two general approaches to explaining our results and other research examining repetition priming in fragment completion and similar tasks. We conclude with discussion of the relation between fragment completion and other tasks believed to measure implicit memory.

Repetition priming has traditionally been explained by postulating temporary activation of an abstract representation of a concept in memory. For example a word's logogen might be activated by presentation of that word (Morton, 1969). Activation of the logogen is assumed to spread to "nearby" related logogens, thus also providing for semantic priming effects (e.g., Neely, 1977). Such an account works quite well for explaining short-lived priming effects, but founders on other phenomena. One example is the finding reported by Winnick and Daniel 
(1970) that tachistoscopic recognition is facilitated by prior visual presentation of an item but not by its prior auditory presentation. Morton (1979; see also Clarke \& Morton, 1983) replicated this finding and abandoned the notion that logogens are abstract, instead postulating separate visual and auditory logogen systems to account for these results. The argument is that the visual presentation of an item primes only the representation in the visual and not in the auditory logogen system, whereas auditory presentation primes only representation in the auditory system. Thus the new formulation of Morton's model predicts no cross-modal priming from prior presentation of items.

Unfortunately, the modified logogen model for repetition priming effects has difficulty accounting for other experimental results, including our own. One difficulty is the long-lasting nature of these effects in our experiment and others (e.g., Jacoby \& Dallas, 1981; Tulving et al., 1982), which seem inconsistent with the temporary activation and fast decay usually postulated by logogen models.

An even more serious problem for the logogen model is the demonstration that other ways of manipulating presentation in addition to modality also provide differential transfer to a later test. In the present experiments, we found specificity of priming produced not only by modality, but also by surface characteristics of the presented items. In two experiments the subjects performed better on a hand-printed test if they had originally studied words in the printed rather than in the typed study condition; in the third experiment similar benefits were obtained when words were studied and tested both in focus or blurred, relative to words studied in one form and tested in the other. Thus various forms of presentation within the visual modality transfer differentially during testing (see also Jacoby, 1983; Jacoby \& Hayman, 1987; Kirsner \& Dunn, 1985; Masson, 1986; Roediger \& Blaxton, 1987). Unless one is willing to postulate a separate logogen system for different typefaces, or for blurred and focused items, then this explanation becomes unworkable, and a simpler alternative should be sought.

Our preferred account of the current findings and similar results revealing dissociations among measures of retention is that advanced in somewhat different forms by Kolers (1976; Kolers \& Roediger, 1984) and Jacoby (1983). Kolers and Roediger (1984) argued that performance in any form of retention test will benefit to the extent that the operations used to encode the stimulus are recapitulated in the retention test. The general idea is thus similar to the concepts of encoding specificity (Tulving \& Thomson, 1973), transfer-appropriate processing (Morris, Bransford, \& Franks, 1977), or, for that matter, stimulus generalization. However, the emphasis in the procedural account is on mental operations. Thus, in accounting for the present results, we assume that mental operations in encoding a word presented visually are different from those involved in encoding words presented auditorily, and thus transfer differentially to performance on the visual fragment completion task. Procedures used in completing fragments are assumed to be more similar to those used in reading, rather than hearing, words during study. In addition, Gardiner (in press) showed that primed word-fragment completion is enhanced if subjects generate a word from a fragment at study rather than read it, providing further evidence that repetition of operations is critical in primed fragment completion.

Similarly, the assumption that different operations are required in encoding words written in different typefaces (Kolers \& Perkins, 1975) accounts for our finding that hand-printed fragments were better completed when words had originally been presented hand-printed rather than typed. The same argument would apply to the results of Experiment 3, in which subjects completed fragments better if the fragment was presented in the same condition (focused or blurred) as the original studied item. Specifying the exact nature of the underlying procedures in these tasks is a vexing if necessary issue for this approach, although our results contribute little to solving this problem.

We believe that a first step in providing more specification lies in the distinction between data-driven and conceptually driven processing (Jacoby, 1983). ${ }^{5}$ Briefly, most implicit memory tasks in their standard form depend on data-driven processing; they should be sensitive to the match in the surface characteristics of presentation format between study and test, and relatively insensitive to conceptual manipulations. On the other hand, most explicit tests benefit from conceptual processes (elaboration, generation, imagery, etc.) and are little affected by altering surface characteristics. ${ }^{6}$ Roediger and Blaxton (1987) reviewed evidence that is largely consistent with this view, and Blaxton (1985), Durgunoglu and Roediger (1986), and Weldon and Roediger (1987) provided further supportive evidence.

The distinction between data-driven and conceptually driven processing should properly be considered as representing endpoints on a continuum, with most tasks involving components of both types of processing. For example, free recall may be considered the purest form of a conceptually driven task because no "data" in the form of cues are provided the subjects at test; perceptual identification may be considered almost purely a datadriven task, because no benefit occurs from having items presented auditorily. Standard recognition tests are largely conceptually driven, in our view, but may involve a datadriven component (Jacoby \& Dallas, 1981; Mandler, 1980) that can be enhanced or reduced depending on experimental conditions and type of material employed (Johnston, Dark, \& Jacoby, 1985). We also believe that word-fragment and word-stem completion tasks are largely data-driven, but that a small conceptual component may also be involved, to account for cross-modal priming in both tasks, among other effects (see Roediger \& Blaxton, 1987; also Roediger \& Weldon, 1987). ${ }^{7}$ The accuracy of this view must await further research. 


\section{REFERENCES}

Blaxton, T. A. (1985), Investigating dissociations among memory measures: Support for a transfer appropriate processing framework. Unpublished doctoral dissertation, Purdue University, West Lafayette, IN.

Clarke, R., \& Morton, J. (1983). Cross modality facilitation in tachistoscopic word recognition. Quarterly Joumal of Experimental Psychology, 35A, 79-96.

Craik, F. I. M., \&ulving, E. (1975). Depth of processing and the retention of words in episodic memory. Journal of Experimental Psychology: General, 104, 268-294.

Dallett, K. M., Wilcox, S. G., \& D’Andrea, L. (1968). Picture memory experiments. Journal of Experimental Psychology, 76, 312-320.

Durgunoglu, A., \& Roediger, H. L. (1987). Test differences in accessing bilingual memory. Joumal of Memory \& Language, 26, 377-391.

GARDINER, J. (in press). Generation and priming effects in word fragment completion. Journal of Experimental Psychology: Learning, Memory, \& Cognition.

Gardiner, J. M., \& GreGg, V. H. (1979). When auditory memory is not overwritten. Journal of Verbal Learning \& Verbal Behavior, 18, 705-719.

Graf, P., \& Mandler, G. (1984). Activation makes words more accessible, but not necessarily more retrievable. Joumal of Verbal Learning \& Verbal Behavior, 23, 553-568.

Graf, P., Mandier, G., \& Haden, P. (1982). Simulating amnesic symptoms in normal subjects. Science, 218, 1243-1244.

Graf, P., \& Schacter, D. L. (1985). Implicit and explicit memory for new associations in normal and amnesic subjects. Journal of Experimental Psychology: Learning, Memory, \& Cognition, 11, 501-518.

Graf, P., SQuire, L. R., Mandler, G. (1984). The information that amnesic patients do not forget. Journal of Experimental Psychology: Learning, Memory, \& Cognition, 10, 164-178.

Graf, P., Shimamura, A. P., \& Squire, L. R. (1985). Priming across modalities and priming across category levels: Extending the domain of preserved function in amnesia. Journal of Experimental Psychology: Learning, Memory, \& Cognition, 11, 386-396.

JACOBY, L. L. (1983). Remembering the data: Analyzing interactive processes in reading. Journal of Verbal Learning \& Verbal Behavior, $22,485-508$.

JACOBY, L. L., \& DALLAS, M. (1981). On the relationship between autobiographical memory and perceptual learning. Joumal of Experimental Psychology: General, 110, 306-340.

JACOBY, L. L., \& HAYMAN, C. A. G. (1987). Specific visual transfer in word identification: Effects of word shape. Journal of Experimental Psychology: Learning, Memory, \& Cognition, 13, 456-463.

JACOBY, L. L., \& WitherSPOON, D. (1982). Remembering without awareness. Canadian Journal of Psychology, 36, 300-324.

JoHnston, W. H., DARK, V. J., \& JACOBY, L. (1985). Perceptual fluency and recognition judgments. Journal of Experimental Psychology: Leaming, Memory, \& Cognition, 11, 3-11.

KIRSNER, K. (1974). Modality differences in recognition memory for words and their attributes. Journal of Experimental Psychology, 102, 579-584.

Kirsner, K., \& DunN, J. C. (1985). The perceptual record: A common factor in repetition priming and attribute retention. In M. I. Posner \& O. S. M. Marin (Eds.), Mechanisms of attention: Attention and performance $X I$. Hillsdale, NJ: Erlbaum.

Kirsner, K., Milech, D., \& Standen, P. (1983). Common and modality-specific processes in the mental lexicon. Memory \& Cognition, 11, 621-630.

Kolers, P. A. (1975). Specificity of operations in sentence recognition. Cognitive Psychology, 7, 289-306.

Kolers, P. A. (1976). Reading a year later. Journal of Experimental Psychology: Human Learning \& Memory, 2, 554-565.

Kolers, P. A., \& Perkins, D. N. (1975). Spatial and ordinal components of form perception and literacy. Cognitive Psychology, 7, 228-267.

Kolers, P. A., \& Roediger, H. L. (1984). Procedures of mind. Journal of Verbal Learning \& Verbal Behavior, 23, 425-449.
Komatsu, S.-I. \& Ohta, N. (1984). Priming effects in word fragment completion for short- and long retention intervals. Japanese Psychological Research, 26, 194-200.

MandLER, G. (1980). Recognizing: The judgment of previous occurrence. Psychological Review, 87, 252-271.

MAsson, M. E. J. (1986). Identification of typographically transformed words: Instance-based skill acquisition. Journal of Experimental Psychology: Learning, Memory, \& Cognition, 12, 479-488.

MorRIs, C. D., Bransford, J. D., \& FranKs, J. J. (1977). Levels of processing versus transfer appropriate processing. Journal of Verbal Learning \& Verbal Behavior, 16, 519-533.

Morton, J. (1969). Interaction of information in word recognition. Psychological Review, 76, 165-178.

MorToN, J. (1979). Facilitation in word recognition: Experiments causing change in the logogen model. In P. A. Kolers, M. E. Wrolstad, \& H. Bouma (Eds.), Processing of visible language I. New York: Plenum Press.

NeEL.Y, J. H. (1977). Semantic priming and retrieval from lexical memory: Roles of inhibitionless spreading activation and limited capacity attention. Journal of Experimental Psychology: General, 106, 226-254.

RoEdiger, H. L., \& BLAXTon, T. A. (1987). Retrieval modes produce dissociations in memory for surface information. In D. Gorfein \& R. R. Hoffman (Eds.), Memory and cognitive processes: The Ebbinghaus Centennial Conference. Hillsdale, NJ: Erlbaum.

RoEDiGer, H. L., \& WELDON, M. S. (1987). Reversing the picture superiority effect. In M. A. McDaniel \& M. Pressley (Eds.), Imagery and related mnemonic processes: Theories, individual differences, and applications. New York: Springer-Verlag.

SACHS, J. D. (1967). Recognition memory for syntactic and semantic aspects of connected discourse. Perception \& Psychophysics, 2, 437-442.

Shimamura, A. (1986). Priming effects in amnesia: Evidence for a dissociable memory function. Quarterly Journal of Experimental Psychology, 38A, 619-644.

Sloman, S. A., Hayman, C. A. G., Ohta, N., Law, J., \& Tulving, E. (in press). Forgetting in primed fragment completion. Journal of Experimental Psychology: Learning, Memory, \& Cognition.

Tulving, E., Schacter, D. L., Stark, H. A. (1982). Priming effects in word-fragment completion are independent of recognition memory. Journal of Experimental Psychology: Learning, Memory, \& Cognition, 8, 336-342.

Tulving, E., \& ThOMson, D. M. (1973). Encoding specificity and retrieval processes in episodic memory. Psychological Review, 80, 352-373.

Warrington, E. K., \& Weiskrantz, L. (1970). Amnesic syndrome: Consolidation or retrieval? Nature, 228, 629-630.

WELDON, M. S., \& RoEDIGER, H. L. (1987). Altering retrieval demands reverses the picture superiority effect. Memory \& Cognition, 15, 269-280.

WINNICK, W. A., \& DANIEL, S. A. (1970). Two kinds of response priming in tachistoscopic recognition. Journal of Experimental Psychology, 84, 74-81.

\section{NOTES}

1. According to Jacoby's (1983) proposal, recognition may also have a data-driven component, and others have previously proposed that recognition judgments can be made on two different sorts of information (e.g., Mandler, 1980). With regard to modality, Kirsner (1974) found a positive effect of matching study and test modalities on recognition memory performance, possibly indicating a data-driven component in recognition. No effect of modality is typically found in long-term free recall, and such effects that are occasionally reported show better performance with auditory than visual presentation (e.g., Gardiner \& Gregg, 1979).

2. Another group of 64 subjects was given a yes/no recognition test following the same study conditions. Because the recognition results produced little of interest for present purposes, they are not reported here. However, they were briefly described by Roediger and Blaxton (1987). 
3. Similar results were obtained regardless of the ordering of study blocks in the two auditory conditions. That is, performance in the uninstructed auditory condition did not differ whether this block of items preceded or followed the block in which subjects were instructed to imagine the words as typed.

4. The focused/blurred manipulation may involve other aspects in addition to manipulation of visual features. If subjects must "fill in" representations of blurred words, then some constructive activity may be involved, akin to manipulations typically used to study the generation effect.

5. We see Mandler's (1980) distinction between (1) activation and integration of perceptual codes and (2) elaboration of these codes as quite similar to the data-driven/conceptually driven distinction endorsed here.
6. We are not arguing that the data-driven/conceptually driven distinction captures or "explains" Graf and Schacter's (1985) classification of memory tests as implicit and explicit. Indeed, one of us has developed tests that are hybrids: an explicit, data-driven test and an implicit, conceptually driven test (Blaxton, 1985).

7. The tasks are data-driven when involving presentation of isolated words. They would certainly be influenced by conceptual factors in other conditions. For example, the fragment $\mathrm{A}_{\text {__ }} \mathrm{A}_{\text {___ IN }}$ would likely be more frequently and quickly completed if preceded by political killer than if given in isolation, due to conceptual processes.

(Manuscript received July 28, 1986; revision accepted for publication January 5,1987 .) 